\title{
Potential for crustal deformation monitoring using a dense cell phone carrier Global Navigation Satellite System network
}

\author{
Yusaku Ohta ${ }^{1,2,3^{*}}$ (1) and Mako Ohzono ${ }^{4,5}$ (I)
}

\begin{abstract}
Monitoring of crustal deformation provides essential information for seismology and volcanology. For such earth science fields and other purposes, various Global Navigation Satellite System (GNSS) networks have been constructed at the national and regional levels. In Japan, the continuous nationwide GNSS network, the GNSS Earth Observation Network System (GEONET), is operated by the Geospatial Information Authority of Japan. Although GEONET has made a substantial contribution to earth science research, the large spacing of GEONET sites makes it difficult to accurately understand crustal deformation phenomena in some cases. However, cell phone carriers in Japan have constructed independent GNSS networks to improve their positioning services in recent years. In this study, we examine the performance of a GNSS network operated by SoftBank Corp. for crustal deformation monitoring. The network has more than 3300 sites throughout Japan, which is approximately 2.5 times the number of the GEONET sites. To assess the quality of SoftBank's GNSS data, we first analyzed data from Miyagi Prefecture and evaluated the stability of the coordinate time series for nine consecutive days during a quiet (interseismic) period. The calculated standard deviations were approximately the same for both networks. Furthermore, we calculated the displacement between September 2020 and March 2021. The results reveal that almost all SoftBank sites showed a consistent displacement with their surrounding GEONET sites. Next, we analyzed the coseismic deformation associated with the off-Fukushima earthquake ( $M_{\text {JMA }}$ 7.3) on February 13, 2021, in both static and kinematic modes. We obtained a westward coherent displacement along the coastline in both networks, although several outliers were observed for the SoftBank sites. Based on these initial assessments, we conclude that these private sector GNSS sites are useful for crustal deformation monitoring with appropriate data quality control.
\end{abstract}

Keywords: GNSS, Dense network, SoftBank Corp., Quality assessment, 2021 off-Fukushima earthquake Graphical Abstract

\section{Introduction}

Monitoring of crustal deformation is crucial for understanding the status of strain accumulation in areas around a plate boundary, active faults, and volcanoes.

\footnotetext{
*Correspondence: yusaku.ohta.d2@tohoku.ac.jp

${ }^{1}$ Research Center for Prediction of Earthquakes and Volcanic Eruptions, Graduate School of Science, Tohoku University, 6-6 Aza-Aoba, Aoba-ku, Aramaki, Sendai 980-8578, Japan

Full list of author information is available at the end of the article
}

The Global Navigation Satellite System (GNSS) is widely used to capture crustal deformation with a high temporal resolution. Over the past several decades, many GNSS networks have been constructed. For example, regional networks have been established in the United States, which mainly cover seismically and volcanically active areas such as the San Andreas fault system, Aleutian Arc, the Island of Hawai'i, and Yellowstone (e.g., Murray et al. 2019). The station distribution reflects the purpose of these networks to monitor deformation at the regional 
scale. A part of the data from these networks is analyzed in real time and used for earthquake early warning (EEW) (e.g., Murray et al. 2018; Allen and Melgar 2019).

In Japan, the continuous nationwide GNSS network, GNSS Earth Observation Network System (GEONET), is operated by the Geospatial Information Authority of Japan (GSI). GEONET has more than 1300 sites, and the average distance between the GNSS sites is approximately $20-25 \mathrm{~km}$. This dense nationwide GNSS network has revealed various crustal deformation phenomena (e.g., Hashimoto et al. 1996; Heki et al. 1997; Sagiya et al. 2000; Ohta et al. 2004; Nishimura et al. 2013; Ohzono et al. 2015). In recent years, a system has been developed to automatically estimate crustal deformation and fault models of a large earthquake using GEONET data (e.g., Ohta et al. 2012, 2018; Kawamoto et al. 2016, 2017).

However, the number of GEONET sites is not sufficient to capture more details about crustal deformation phenomena. For example, M6 to M7 class earthquakes occurring on inland active faults have fault lengths of approximately $20-40 \mathrm{~km}$. The GEONET site spacing is not sufficient for estimating the fault models of these earthquakes. Ohta et al. (2008a) investigated the coseismic fault model of the 2008 Iwate-Miyagi inland earthquake $\left(\mathrm{M}_{\mathrm{IMA}}\right.$ 7.2). They constructed a dense GNSS network to complement GEONET in monitoring strain accumulation along the inland active fault. The 2008 Iwate-Miyagi inland earthquake occurred within this network, and the fault model estimated from this network suggests that the earthquake occurred at a blind fault. Without network densification, it would have been difficult to estimate an accurate coseismic fault model using GEONET data only (Ohta et al. 2008a). In addition, a campaign GNSS observation was also conducted after the earthquake to observe the postseismic displacement. The results showed that aseismic slip occurred in a different fault from the mainshock (Iinuma et al. 2009). Therefore, the availability of such dense observation data is essential for understanding the physical processes of M6-M7 class seismic events that occur more frequently than larger magnitude events. In recent years, cell phone carriers in Japan have been constructing a GNSS network to upgrade the location information for applications such as automated driving, automated agriculture, and public surveying. For these applications, it is necessary to obtain accurate location information with an error of a few centimeters. For example, one of the Japanese telecommunication providers, SoftBank Corp. (hereafter referred to as "SoftBank"), constructed a dense GNSS network in November 2019. The network has more than 3300 sites, which is approximately 2.5 times the number of GEONET sites. This observation network aims to be a reference station for real-time kinematic (RTK) analysis to obtain high-precision locations for their customers. However, to the best of our knowledge, no study has evaluated the performance of this network in terms of crustal deformation monitoring. Therefore, the purpose of this study was to assess the applicability of SoftBank's dense GNSS network for monitoring crustal deformation. We focused on the initial precision assessment. Geophysical interpretation of the obtained crustal deformation field was kept at a minimum.

\section{GNSS data and its analysis}

SoftBank network GNSS raw data were provided by SoftBank to evaluate the quality of the observation data for crustal deformation monitoring purposes. The raw GNSS data were procured through a contract with SoftBank. SoftBank's GNSS network uses identical GNSS equipment. The equipment has adopted a GNSS receiver and antenna manufactured by Septentrio. The GNSS receiver and antenna are geodetic-grade products and can measure multi-constellation and frequency data. All GNSS receivers and antennas are installed at cell phone base stations. Owing to the contract between SoftBank and us, we were unable to disclose more detailed information about these GNSS observation equipment and monumentation.

For real-time applications, the original phase and code data are recorded for the Global Positioning System (GPS), Quasi-Zenith Satellite System, Global Navigation Satellite System (GLONASS), Galileo, and BeiDou; the data have a sampling interval of $1 \mathrm{~s}$. However, to analyze the data in the static mode for daily coordinate time series, only GPS data were used in this study to facilitate the interpretation of the analysis results. For comparison, the surrounding raw data of GEONET sites were analyzed together with the data of the SoftBank sites.

We analyzed data of two different datasets to evaluate the ability of the very dense SoftBank GNSS network to monitor crustal deformation. The first dataset was from a quiet period in Miyagi Prefecture, northeastern Japan. The second dataset covered a coseismic period of the offFukushima earthquake $\left(\mathrm{M}_{\mathrm{JMA}}\right.$ 7.3) that occurred on February 13, 2021. More details of the data and their analysis are provided in the following sections.

\section{Evaluation of daily coordinate stability of SoftBank data}

A massive Mw 9.0 earthquake occurred beneath the Pacific Ocean near northeastern Japan on March 11, 2011. After this event, long-term deformation was clearly observed (e.g., Sun et al. 2014). To examine the daily coordinate stability of SoftBank data and their consistency with GEONET data, we analyzed data from nine consecutive days in September 2020 and March 2021 in Miyagi Prefecture. The number of observation sites was 
64 and 30 for SoftBank and GEONET, respectively. Figure $1 \mathrm{~b}$ shows the distribution of these sites. As described in the previous section, SoftBank's GNSS network began operation in November 2019. Therefore, we calculated the difference in daily coordinates between the average daily coordinates for September 21-30, 2020, and the average daily coordinates for March 21-30, 2021.

\section{Evaluation of detectability of coseismic displacement}

To examine the performance of the SoftBank network in monitoring coseismic deformation, we chose the offFukushima earthquake $\left(\mathrm{M}_{\mathrm{JMA}}\right.$ 7.3) that occurred on February 13, 2021, at 14:07:50.5 (UTC) and was one of the most significant events after the installation of the SoftBank network. The Centroid Moment Tensor (CMT) solution, estimated by F-net of the National Research Institute for Earth Science and Disaster Resilience (NIED), suggested a reverse fault-type mechanism with a west-northwest and east-southeast compression axis. The site distribution is shown in Fig. 1c. We calculated the difference between the daily coordinates on February 12 and 14 to obtain the coseismic displacement.

\section{GNSS data analysis}

We estimated the GEONET and SoftBank sites' daily coordinate time series through conventional baseline analysis using the Bernese GNSS Software version 5.2 (Dach et al. 2015). The provided raw data included GPS and GLONASS dual-frequency data, but only GPS data were used in this analysis. We adopted the final precise satellite orbits and earth rotation parameters provided by the International GNSS Service (IGS).

To correct for phase center variation of ground sites and GPS satellites, we applied the absolute antenna phase center variation table provided by the IGS. The estimated daily coordinates were constrained by the International Terrestrial Reference Frame 2014 (ITRF2014, Altamimi et al. 2016) with four neighboring IGS sites around Japan. The zenith tropospheric delay and the tropospheric gradient were estimated every two hours. Carrier-phase ambiguities were resolved through different methods depending on the baseline length. When the baseline was longer than $20 \mathrm{~km}$, it was solved with the quasiionosphere-free ambiguity resolution. In contrast, if the baseline was shorter than $20 \mathrm{~km}$, direct L1/L2 ambiguity resolution was applied. This method follows the standard analysis method in the Bernese GNSS software (RNX2SNX.PCF in Dach et al. 2015). Finally, we calculated the displacement relative to the GEONET 950241 site (Ogata in Niigata Prefecture, latitude $37.231^{\circ} \mathrm{N}$, longitude $\left.138.334^{\circ} \mathrm{E}\right)$.

In view of the application of GNSS as a strong-motion seismometer, PPP kinematic analysis was also performed on the data from several sites for the 2021 off-Fukushima earthquake. We used RTKLIB (Takasu and Yasuda 2009) ver. 2.4.3. We adopted the Center for Orbit Determination in Europe's final precise orbit and clock correction for every $5 \mathrm{~s}$. Both GPS and GLONASS data were used for this analysis.

\section{Results and discussion}

\section{Stability of daily coordinate time series}

First, we assessed the stability of the estimated time series to evaluate the quality of SoftBank's GNSS data. Figure $2 \mathrm{a}-\mathrm{c}$ shows the standard deviation (SD) between September 22 and 30, 2020, for the three components (east-west [EW], north-south [NS], and up-down [UD]) in Miyagi prefecture. To create the figure, we assumed
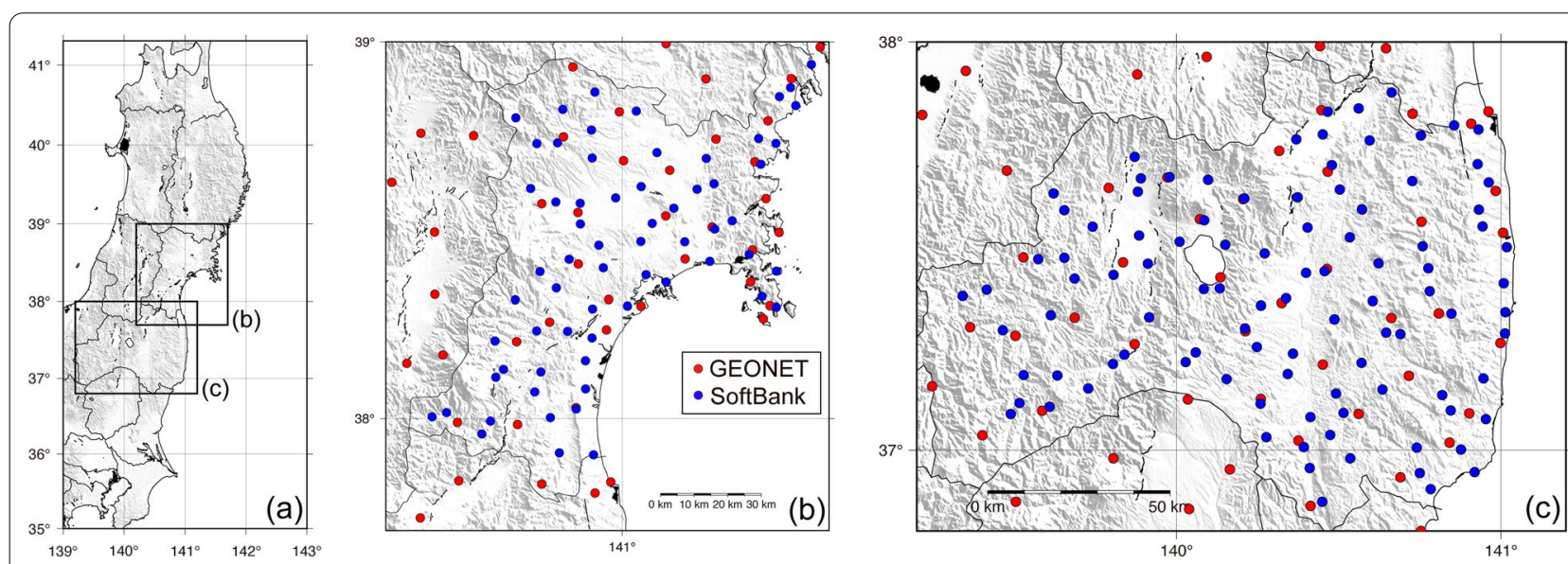

Fig. 1 Site distribution for this research. The red and blue circles denote GEONET and SoftBank sites, respectively. a Index map for the target area. $\mathbf{b}$ Site distribution in Miyagi Prefecture for the postseismic (interseismic) period. c Site distribution in Fukushima Prefecture for the coseismic period 

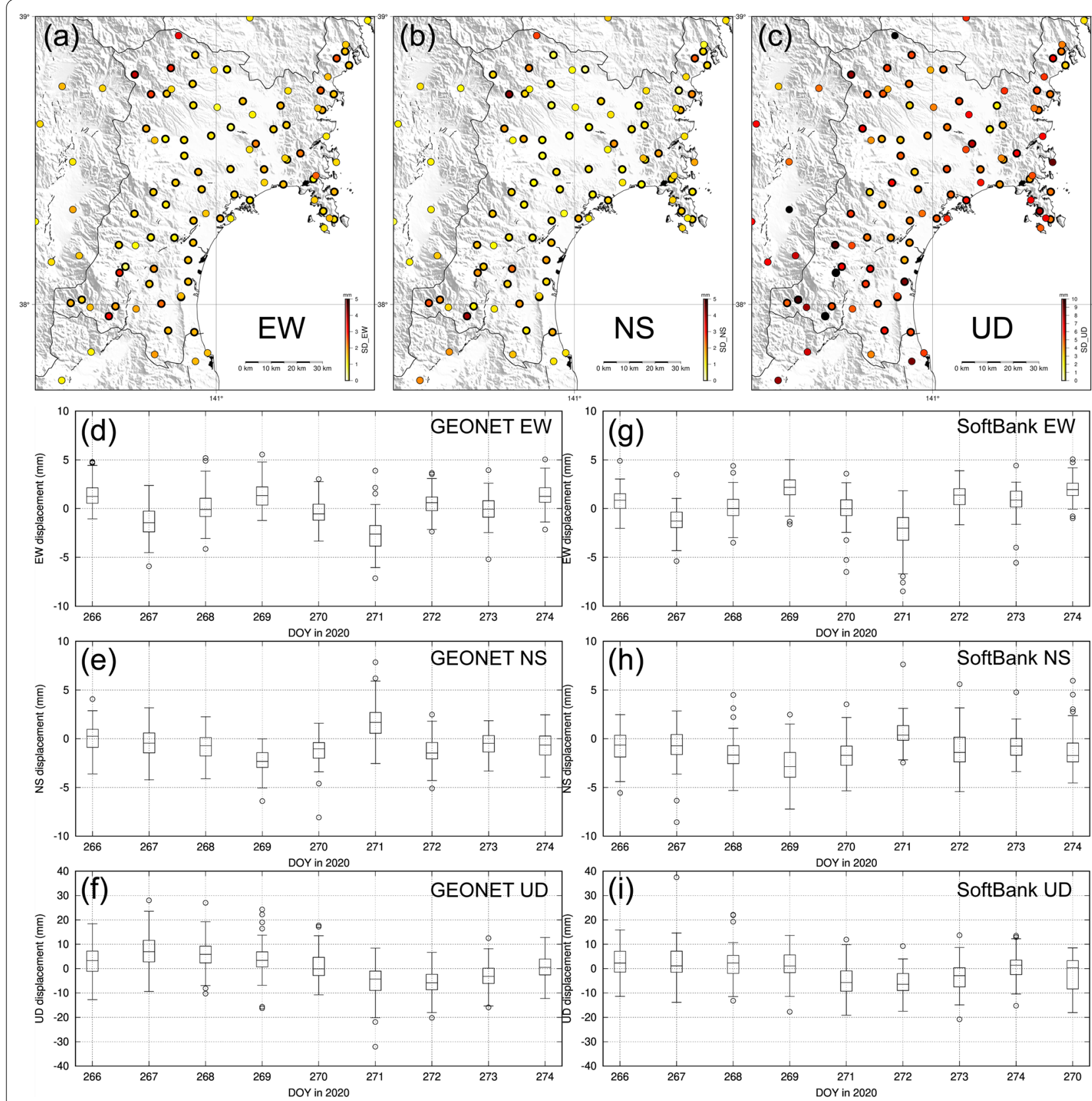

Fig. 2 a-c Standard deviation (SD) for September 22-30, 2020, for three components in Miyagi Prefecture. Thin and thick black outlines show the GEONET and SoftBank sites, respectively. a East-west component, $\mathbf{b}$ north-south component, and $\mathbf{c}$ up-down component. $\mathbf{d}$-i Box-and-whisker plots of daily coordinate time series in Miyagi Prefecture during days 266 to 274 in 2020. The left and right columns show GEONET and SoftBank, respectively. Small circles denote outliers, defined when there was a distance of 1.5 times the interquartile range (IQR) value

September 21, 2020 (day of year, 265) as the reference day for all stations. There were no significant earthquake events during this period. The averaged SD of all SoftBank time series was 1.7, 1.6, and $5.3 \mathrm{~mm}$ for the EW, NS, and UD components, respectively. Similarly, the averaged SD of all GEONET time series was 1.6, 1.4, and $5.9 \mathrm{~mm}$ for the EW, NS, and UD components, respectively. The calculated SDs were approximately the same for each network.

Furthermore, box-and-whisker plots were developed for each observation network to compare the daily time series variability of all stations (Fig. $2 \mathrm{~d}-\mathrm{i}$ ). Outliers were defined as data exceed 1.5 times the interquartile range (IQR) value. When we evaluated the day-to-day 
variability, the number of outliers was slightly higher for the SoftBank network. The number of outliers for the EW, NS, and UD components was 19, 8, and 17, respectively, for GEONET, and 22, 16, and 13 for SoftBank, respectively. The range of the upper and lower quartiles between the networks was similar. These results suggest that the stability of the time series of the SoftBank network data may be sufficient to monitor crustal deformation.

Figure 3 shows the displacement between the averages for September 21-30, 2020, and March 21-30, 2021. Note that the duration was approximately half a year. A significant trenchward displacement and clear uplift in the forearc region appeared in the horizontal and vertical components, respectively. These characteristics mainly reflect the viscoelastic relaxation of the 2011 Tohoku-Oki earthquake (e.g., Suito 2017). Almost all sites showed a consistent displacement with their surroundings. However, several sites showed anomalous displacements. To determine whether these data represent crustal deformation properly, they need to be examined more rigorously using extended time series.

\section{Detectability of coseismic displacement}

Figure 4 shows the horizontal coseismic displacement of the 2021 off-Fukushima earthquake. A westward coherent displacement appeared along the coastline. In contrast, several outliers at the SoftBank sites were also confirmed. For example, the BHC0 site, $50 \mathrm{~km}$ away from the coastline, showed a westward displacement of approximately $20 \mathrm{~mm}$, although the surrounding sites showed almost zero displacement (Fig. 4).

Figure 5 shows the displacement time series of $\mathrm{BH} 7 \mathrm{H}$ and BHCO. We compared these SoftBank GNSS sites and nearby strong-motion seismometer sites (NIED K-net FKS007 and FKS019, sampling frequency: $100 \mathrm{~Hz}$ ) (Fig. 5). The distance between the SoftBank GNSS and NIED K-net sites is $4.3 \mathrm{~km}$ for BH7H and FKS007, and $5.9 \mathrm{~km}$ for BHCO and FKS019, respectively (Fig. 4). In the comparison between the two time series, the strongmotion seismometer time series was integrated twice. For FKS019, a large undulation clearly appeared in the integrated time series in the EW and NS component (Fig. 5b). Thus, a high-pass filter with a corner frequency of $0.05 \mathrm{~Hz}$ was applied for the integrated time series of FKS019 in the EW and NS components. The displacement waveforms of $\mathrm{BH} 7 \mathrm{H}$ and $\mathrm{FKS007}$ are basically consistent with each other. But the waveform of FKS007 suffered from a low-frequency bias caused by the integration while the shaking of $\mathrm{BH} 7 \mathrm{H}$ lasts longer until the latter half of the time series. The latter may reflect a resonance of the cell phone base station caused by the strong motion or other local site effects.
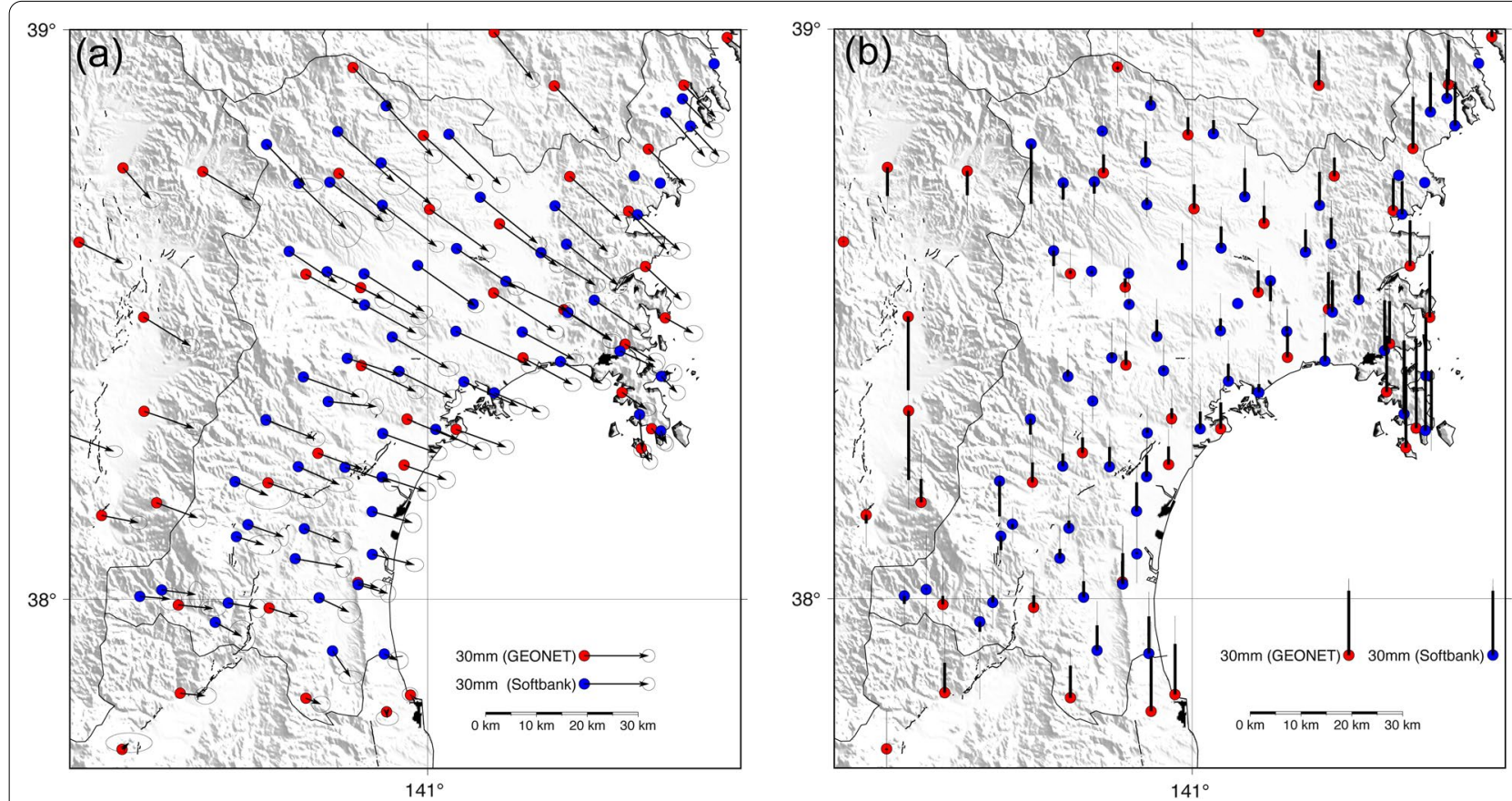

Fig. 3 Displacement field between the averages for September 21-30, 2020, and March 21-30, 2021. The red and blue circles denote the GEONET and SoftBank sites, respectively. The vectors plotted in the figures are those relative to 950241 (Ogata in Niigata Prefecture, latitude $37.231^{\circ} \mathrm{N}$, longitude $\left.138.334^{\circ} \mathrm{E}\right)$. a Horizontal component, $\mathbf{b}$ vertical component. The error ellipsoid and bars indicate the one sigma confidential level 


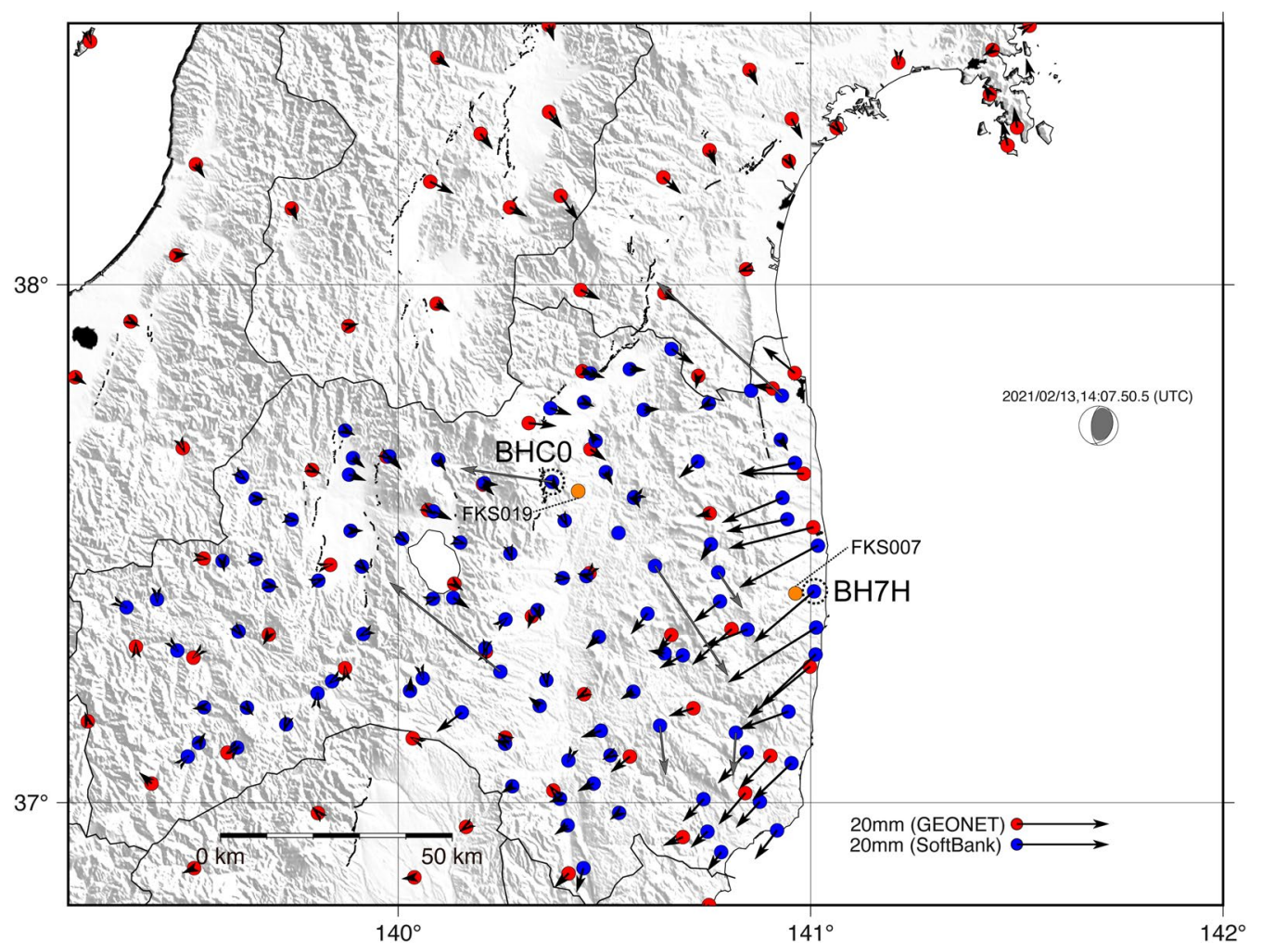

Fig. 4 Horizontal coseismic displacement of the 2021 off-Fukushima earthquake ( $M_{\text {JMA }}$ 7.3). The red and blue circles denote the GEONET and SoftBank sites, respectively. The orange circles denote K-net FKS007 and FKS019. The vectors plotted in the figures are those relative to 950241 (Ogata in Niigata prefecture, latitude $37.231^{\circ} \mathrm{N}$, longitude $138.334^{\circ} \mathrm{E}$ ). The CMT solution was estimated F-net of the NIED. Gray vectors represent the outliers identified by comparing them with the surrounding sites. The sites of SoftBank, $\mathrm{BH} 7 \mathrm{H}$ and BHCO, are indicated by a thick dashed black open circle, and the details of this point are provided in the Sect. "Detectability of coseismic displacement"
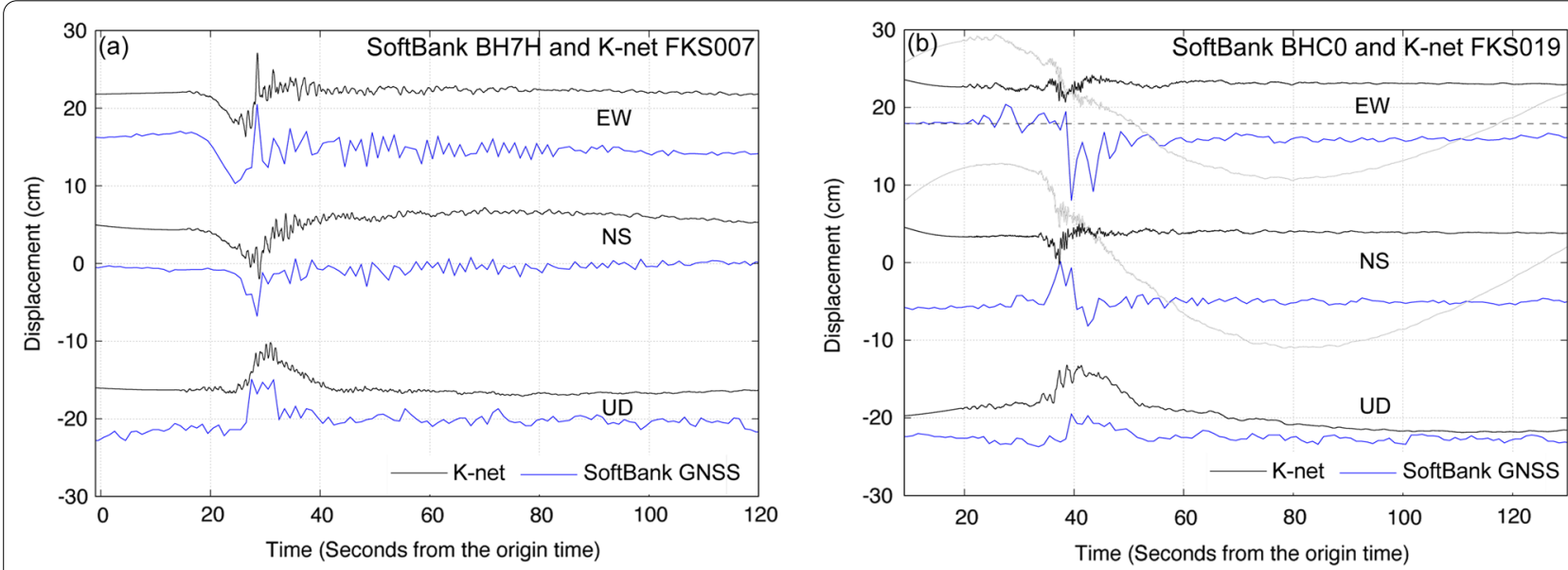

Fig. 5 Kinematic PPP analysis time series in $\mathrm{BH} 7 \mathrm{H}$ and $\mathrm{BHCO}$ during the 2021 off-Fukushima earthquake $\left(\mathrm{M}_{\mathrm{JMA}}\right.$ 7.3). For comparison, the time series of the K-net FKS007 and FKS019 strong motion records, which are close to BH7H and BHCO, respectively, are also shown. The horizontal axis indicates the lapse time from the origin time [February 13, 2021, 14:07:50.5 (UTC)]. The vertical axis indicates the displacement in EW, NS, and UD from top to bottom. a Kinematic time series of BH7H and K-net FKS007 strong-motion time series. The blue and black lines denote the BH7H and integrated FKS007 time series, respectively. $\mathbf{b}$ Kinematic time series of BHCO and K-net FKS019 strong-motion time series. The blue line denotes the BHCO time series. The gray line denotes the integrated FKS019 time series of the EW and NS. The black line denotes the high-pass filtered time series with a corner frequency of $0.05 \mathrm{~Hz}$ applied to the integrated time series except for the UD. No high-pass filter was applied to the UD component. The black dashed line in the EW component in the kinematic PPP time series denotes the reference position before the earthquake 
Figure $5 \mathrm{~b}$ shows the time series of BHCO and FKS019, where $\mathrm{BHC} 0$ showed a displacement different from that of the surrounding sites based on the daily coordinate analysis. The EW components in $\mathrm{BHCO}$ exhibited a permanent westward displacement after the S-wave arrival. This result suggested that the westward displacement of the GNSS antenna may not have occurred by coincidence because of variations in the analysis, but may have been caused by the westward displacement of the GNSS antenna. In addition, the amplitude of the displacement time series due to the seismic wave was clearly larger in BHC0 than in FKS019. These results may suggest that the mounting of $\mathrm{BHCO}$ to the ground is unstable. There are previous studies on these unexpected abnormal displacements that differ from surrounding sites during and after an earthquake. Ohta et al. (2008b) found a localized abnormal coseismic and postseismic displacement in a GEONET site after the 2007 Chuetsu-Oki earthquake $\left(M_{\mathrm{IMA}} 6.8\right)$ in central Japan. They installed another campaign GNSS site near the GEONET site to evaluate the displacement. Based on short baseline analysis, they concluded that a small-scale landslide occurred after the mainshock due to strong shaking. Such monumentation instability may also occur in private sector GNSS networks such as SoftBank. In GEONET, tiltmeters are installed inside the pillars (Munekane 2013), against which a comparison can be made for unexpected displacement caused by strong shaking. In the case of SoftBank, it is necessary to utilize a screening approach that takes advantage of a very dense network and its inconsistency with the surrounding observation sites. For example, it is considered that an algorithm should be developed to exclude specific sites that show an amount and direction of displacement that is obviously not in accordance with the surrounding GNSS sites within a certain threshold. The stability of mounting might also be investigated by exhaustively examining the relationship between the noise level and wind speed in kinematic time series based on long-term observation data. On the basis of such quality inspection, the SoftBank network can be used to observe not only static offsets by an earthquake, but also dynamic displacement.

\section{Looking ahead}

As demonstrated, the dense GNSS network operated by SoftBank, a private sector company, can be basically used for crustal deformation monitoring with reasonable precision. The use of the SoftBank network in addition to GEONET can considerably improve the spatial resolution of crustal deformation monitoring. For example, GEONET has 38 sites, whereas SoftBank has 99 sites in Fukushima Prefecture. The area of Fukushima Prefecture is approximately $13,780 \mathrm{~km}^{2}$, and the area per site of GEONET is $363 \mathrm{~km}^{2}$. The area per site of SoftBank is $139 \mathrm{~km}^{2}$ and becomes $101 \mathrm{~km}^{2}$ when combined with GEONET sites. When both are used together, there is, on average, one GNSS site in a circle with a radius of approximately $5.7 \mathrm{~km}$. Shen et al's (1996) method is often used to estimate the spatial characteristics of strain based on velocity fields of a GNSS site. They estimated strain fields through bilinear fitting with weighted contributions of data according to the distance to an estimation point. To estimate the strain field, it is necessary to assume a hyperparameter (named as "distance decay constant") for weighting according to distance. This value is generally assumed using the spacing of GNSS sites (e.g., Meneses-Gutierrez and Sagiya 2016). In other words, the combined use of GEONET and SoftBank sites will enable us to understand crustal strain with a higher spatial resolution.

The purpose of the SoftBank network is to provide a location information service with high accuracy and precision in real-time. The data from the SoftBank network are already distributed in real-time using NTRIP (Networked Transport of RTCM via Internet Protocol) format for a charge, and real-time analysis of these data will enable us to monitor crustal deformation in realtime. As described in the Introduction, the GSI is already operating a real-time GNSS analysis and automatic fault modeling system for crustal deformation monitoring. If real-time analysis of GNSS sites of private companies such as SoftBank can be performed simultaneously, it will not only function as a system complementary to GEONET, but also contribute to the estimation of a more detailed fault model. In addition, such a dense real-time GNSS network may be utilized for EEW based on realtime GNSS analysis (e.g., Allen and Melgar 2019).

Finally, data quality control is important. The GSI established the "Performance Standards and Registration Guidelines for GNSS Sites in the Private Sector" in October 2019 (Geospatial Information Authority of Japan 2019) as a system to evaluate the performance of GNSS continuous sites in the private sector and register the sites by classification. Registration makes it possible to use private sector GNSS data that are consistent with national coordinates and have a certain accuracy and precision. By confirming the stability of the observation sites while continuing quality control, we believe that private sector GNSS sites can be used in a wide range of earth science fields, not only in crustal deformation but also in tropospheric, ionospheric, and other studies.

\section{Conclusions}

We evaluated the precision of a private sector GNSS network operated by SoftBank Corp. for crustal deformation monitoring. To assess the network, we analyzed 
two different targets. The first target was a postseismic (interseismic) period in Miyagi Prefecture. We assessed the stability of the estimated time series to evaluate the quality of SoftBank's GNSS data for 9 days. The calculated SDs were similar for each network. Furthermore, we calculated the displacement between September 2020 and March 2021. As a result, almost all sites showed a consistent displacement with their surroundings. The second target was the coseismic period of the off-Fukushima earthquake $\left(\mathrm{M}_{\mathrm{IMA}}\right.$ 7.3) that occurred on February 13, 2021. When we calculated the coseismic displacement, we obtained a westward coherent displacement along the coastline in both networks. In contrast, several outliers in the sites of SoftBank were also confirmed. Based on the $1-\mathrm{Hz} \mathrm{kPPP}$ analysis for one of these outliers, we identified a possible localized deformation in the site. On the contrary, the nearest strong-motion record and the record of the station that showed a crustal deformation consistent with that of the surrounding area were in good agreement. We conclude that by a continued data quality control, these private sector GNSS sites can be used for crustal deformation monitoring.

\begin{abstract}
Abbreviations
CMT: Centroid moment tensor; GEONET: GNSS Earth Observation Network System; GNSS: Global Navigation Satellite System; GSI: Geospatial Information Authority of Japan; JMA: Japan Meteorological Agency; NIED: National Research Institute for Earth Science and Disaster Resilience; EEW: Earthquake early warning; RTK: Real-time kinematic; GPS: Global Positioning System; GLONASS: Global Navigation Satellite System; EW: East-west; NS: North-south; UD: Up-down; SD: Standard deviation; kPPP: Kinematic precise point positioning; NTRIP: Networked Transport of RTCM via Internet Protocol.
\end{abstract}

\section{Acknowledgements}

We are grateful to SoftBank Corp. for providing us with the original GNSS network data. We also thank the GSI for providing GEONET data. Strong motion data from K-NET were provided by the NIED. We would like to thank the anonymous reviewers and the editor for their constructive comments on the manuscript. This work was supported by the JST FOREST Program (Grant Number: JPMJFR202P, Japan). In addition, this study was also supported by the Ministry of Education, Culture, Sports, Science and Technology (MEXT) of Japan, under its The Second Earthquake and Volcano Hazards Observation and Research Program (Earthquake and Volcano Hazard Reduction Research). We would like to thank Editage (www.editage.com) for English language editing.

\section{Authors' information}

Y.O. is an associate professor at the Graduate School of Science, Tohoku University. M.O. is an associate professor at the Graduate School of Science, Hokkaido University, and Earthquake Research Institute, the University of Tokyo.

\section{Authors' contributions}

YO and $\mathrm{MO}$ designed the study and analyzed the data. Both authors read and approved the final manuscript.

\section{Funding}

This work was supported by the JST FOREST Program (Grant Number: JPMJFR202P, Japan). In addition, this study was also supported by the Ministry of Education, Culture, Sports, Science and Technology (MEXT) of Japan, under its The Second Earthquake and Volcano Hazards Observation and Research Program (Earthquake and Volcano Hazard Reduction Research). This study was also partially supported by ERI JURP 2020-B-03 in Earthquake Research Institute, the University of Tokyo.

\section{Availability of data and materials}

The GNSS data of SoftBank Corp. supporting the findings of this study are available from SoftBank Corp., but restrictions apply to the availability of these data, which were used under license for the current study. The GNSS data of the GSI are available on their web page (www.gsi.go.jp). Strong motion data from K-NET are available on their web page (www.bosai.go.jp). The analyzed data for the current study are available from the corresponding author upon reasonable request.

\section{Declarations}

Ethics approval and consent to participate

Not applicable

\section{Consent for publication}

Not applicable

\section{Competing interests}

The authors declare that they have no competing interests.

\section{Author details}

${ }^{1}$ Research Center for Prediction of Earthquakes and Volcanic Eruptions, Graduate School of Science, Tohoku University, 6-6 Aza-Aoba, Aoba-ku, Aramaki, Sendai 980-8578, Japan. ${ }^{2}$ Division for the Establishment of Frontier Sciences of Organization for Advanced Studies, Tohoku University, 2-1-1 Katahira, Aoba-ku, Sendai 980-8577, Japan. ${ }^{3}$ International Research Institute of Disaster Science, Tohoku University, Aoba 468-1, Aramaki, Aoba-ku, Sendai 980-8572, Japan. ${ }^{4}$ Institute of Seismology and Volcanology, Faculty of Science, Hokkaido University, N10W8, Kita-Ku, Sapporo, Hokkaido 060-0810, Japan. ${ }^{5}$ Earthquake Research Institute, the University of Tokyo, 1-1-1 Yayoi, Bunkyo-ku, Tokyo 113-0032, Japan.

Received: 16 November 2021 Accepted: 25 January 2022

Published online: 09 February 2022

\section{References}

Allen RM, Melgar D (2019) Earthquake early warning: advances, scientific challenges, and societal needs. Annu Rev Earth Planet Sci 47:361-388. https:// doi.org/10.1146/annurev-earth-053018-060457

Altamimi Z, Rebischung P, Métivier L, Collilieux X (2016) ITRF2014: a new release of the International Terrestrial Reference Frame modeling nonlinear station motions. J Geophys Res 121:6109-6131. https://doi.org/10. 1002/2016JB013098

Dach R, Lutz S, Walser P, Fridez P (ed) (2015) Bernese GNSS software version 5.2 User manual, Astronomical Institute, University of Bern Open Publishing. doi:https://doi.org/10.7892/boris.72297

Geospatial Information Authority of Japan (2019) Performance Standards and Registration Guidelines for GNSS Sites in the Private Sector (in Japanese) https://www.gsi.go.jp/common/000228654.pdf, Accessed 15 Nov 2021.

Hashimoto M, Sagiya T, Tsuji H, Hatanaka Y, Tada T (1996) Coseismic Displacements of the 1995 Hyogo-ken Nanbu Earthquake. J Phys Earth 44(4):255-279. https://doi.org/10.4294/jpe1952.44.255

Heki K, Miyazaki S, Tsuji H (1997) Silent fault slip following an interplate thrust earthquake at the Japan Trench. Nature 386:595-598. https://doi.org/10. 1038/386595a0

linuma T, Ohzono M, Ohta Y, Miura S, Kasahara M, Takahashi H, Sagiya T, Matsushima T, Nakao S, Ueki S, Tachibana K, Sato T, Tsushima H, Takatsuka K, Yamaguchi T, Ichiyanagi M, Takada M, Ozawa K, Fukuda M, Asahi Y, Nakamoto M, Yamashita Y, Umino N (2009) Aseismic slow slip on an inland active fault triggered by a nearby shallow event, the 2008 Iwate-Miyagi Nairiku earthquake (Mw6.8). Geophys Res Lett 36:1-5. https://doi.org/10. 1029/2009GL040063

Kawamoto S, Hiyama Y, Ohta Y, Nishimura T (2016) First result from the GEONET real-time analysis system (REGARD): The case of the 2016 
Kumamoto earthquakes. Earth Planets Space 68:1-12. https://doi.org/10. 1186/s40623-016-0564-4

Kawamoto S, Ohta Y, Hiyama Y, Todoriki M, Nishimura T, Furuya T, Sato Y, Yahagi T, Miyagawa K (2017) REGARD: A new GNSS-based real-time finite fault modeling system for GEONET. J Geophys Res Solid Earth 122:1324-1349. https://doi.org/10.1002/2016JB013485

Meneses-Gutierrez A, Sagiya T (2016) Persistent inelastic deformation in central Japan revealed by GPS observation before and after the Tohoku-oki earthquake. Earth Planet Sci Lett 450:366-371. https://doi.org/10.1016/j. epsl.2016.06.055

Munekane H (2013) Sub-daily noise in horizontal GPS kinematic time series due to thermal tilt of GPS monuments. J Geod 87:393-401. https://doi. org/10.1007/s00190-013-0613-8

Murray JR, Crowell BW, Grapenthin R, Hodgkinson K, Langbein JO, Melbourne T, Melgar D, Minson SE, Schmidt DA (2018) Development of a geodetic component for the U.S. West Coast earthquake early warning system. Seismol Res Lett 89:2322-2336. https://doi.org/10.1785/0220180162

Murray JR, Bartlow N, Bock Y, Brooks BA, Foster J, Freymueller J, Hammond WC, Hodgkinson K, Johanson I, López-Venegas A, Mann D, Mattioli GS, Melbourne T, Mencin D, Montgomery-Brown E, Murray MH, Smalley R, Thomas V (2019) Regional global navigation satellite system networks for crustal deformation monitoring. Seismol Res Lett 91:552-572. https://doi. org/10.1785/0220190113

Nishimura T, Matsuzawa T, Obara K (2013) Detection of short-term slow slip events along the Nankai Trough, southwest Japan using GNSS data. J Geophys Res Solid Earth 118:3112-3125. https://doi.org/10.1002/jgrb. 50222

Ohta Y, Kimata F, Sagiya T (2004) Reexamination of the interplate coupling in the Tokai region, central Japan, based on the GPS data in 1997-2002. Geophys Res Lett 31:1999-2002. https://doi.org/10.1029/2004GL021404

Ohta Y, Miura S, linuma T, Tachibana K, Matsushima T, Takahashi H, Sagiya T, Ito T, Miyazaki S, Doke R, Takeuchi A, Miyao K, Hirao A, Maeda T, Yamaguchi T, Takada M, Iwakuni M, Ochi T, Meilano I, Hasegawa A (2008a) Coseismic and postseismic deformation related to the 2007 Chuetsu-oki, Niigata Earthquake. Earth Planets Space 60:1081-1086. https://doi.org/10.1186/ BF03353140

Ohta Y, Ohzono M, Miura S, linuma T, Tachibana K, Takatsuka K, Miyao K, Sato T, Umino N (2008b) Coseismic fault model of the 2008 Iwate-Miyagi Nairiku earthquake deduced by a dense GPS network. Earth Planets Space 60:1197-1201. https://doi.org/10.1186/BF03352878

Ohta Y, Kobayashi T, Tsushima H, Miura S, Hino R, Takasu T, Fujimoto H, linuma T, Tachibana K, Demachi T, Sato T, Ohzono M, Umino N (2012) Quasi realtime fault model estimation for near-field tsunami forecasting based on RTK-GPS analysis: Application to the 2011 Tohoku-Oki earthquake (Mw 9.0). J Geophys Res 117(B2):B02311. https://doi.org/10.1029/2011JB0087 50

Ohta Y, Inoue T, Koshimura S, Kawamoto S, Hino R (2018) Role of real-time GNSS in near-field tsunami forecasting. J Disaster Res 13:453-459. https:// doi.org/10.20965/jdr.2018.p0453

Ohzono M, Takahashi H, Ichiyanagi M (2015) An intraplate slow earthquake observed by a dense GPS network in Hokkaido, northernmost Japan. Geophys J Int 200:144-148. https://doi.org/10.1093/gji/ggu380

Sagiya T, Miyazaki S, Tada T (2000) Continuous GPS array and present-day crustal deformation of Japan. Pure Appl Geophys 157:2303-2322. https:// doi.org/10.1007/PL00022507

Shen ZK, Jackson DD, Ge BX (1996) Crustal deformation across and beyond the Los Angeles basin from geodetic measurements. J Geophys Res 101(27957-27980):980. https://doi.org/10.1029/96JB02544

Suito $\mathrm{H}$ (2017) Importance of rheological heterogeneity for interpreting viscoelastic relaxation caused by the 2011 Tohoku-Oki earthquake. Earth Planets Space. https://doi.org/10.1186/s40623-017-0611-9

Sun T, Wang K, linuma T, Hino R, He J, Fujimoto H, Kido M, Osada Y, Miura S, Ohta Y, Hu Y (2014) Prevalence of viscoelastic relaxation after the 2011 Tohoku-oki earthquake. Nature 514:84-87. https://doi.org/10.1038/natur e13778

Takasu T, Yasuda A (2009) Development of the low-cost RTK-GPS receiver with an open source program package RTKLIB. International Symposium on GPS/GNSS, International Convention Center Jeju, Korea, Nov 4-6

\section{Publisher's Note}

Springer Nature remains neutral with regard to jurisdictional claims in published maps and institutional affiliations.

\section{Submit your manuscript to a SpringerOpen ${ }^{\circ}$ journal and benefit from:}

- Convenient online submission

- Rigorous peer review

- Open access: articles freely available online

- High visibility within the field

- Retaining the copyright to your article

Submit your next manuscript at $\boldsymbol{\nabla}$ springeropen.com 